\title{
Designing an Innovative Business Model of the Regional Services Sector
}

\author{
Smirnov V.V.* \\ Chuvash State University \\ Cheboksary, Russia \\ e-mail: walera712006@mail.ru \\ Zakharova A.N. \\ Chuvash State University \\ Cheboksary, Russia \\ e-mail: zaharova_an@mail.ru
}

\author{
Semenov V.L. \\ Chuvash State University \\ Cheboksary, Russia
}

\author{
Lavina T.A. \\ Chuvash State University \\ Cheboksary, Russia
}

\author{
Dulina G.S. \\ Chuvash State University \\ Cheboksary, Russia
}

\begin{abstract}
The subject of the study is an innovative business model of the regional service sector (IBMRSS). The aim of the work is the formation of methodological provisions for the design of IBMRSS. The article systematizes the IBMRSS management problem. As a result of the research, the following tasks were solved: we considered and substantiated the necessity of designing IBMRSS; disclosed the essence and design concept of IBMRSS; formulated the theoretical provisions of IBMRSS design and explained the main categories; proposed a methodology for assessing the effectiveness of using the innovative potential of the regional services sector and formulated the principles of its functioning; proposed the procedure for performing an expert assessment; identified patterns of development of organizational structures of the service sector that affect its functionality; presented and explained IBMRSS and formulated a general concept of its materialization. The article considers IBMRSS as purposeful process management of innovative development of business entities. These entities form a geographically separate economic space together, consisting of an interconnected variety of activities that consolidate into a single oriented aggregate, with an aim to ensure innovative development. The proposed methodology for assessing the effectiveness of using the innovative potential of the regional services sector allows us to reflect on the state and prospects of IBMRSS implementation, and to adjust the dynamics of innovative development of business entities in the regional services sector in accordance with objective economic laws and patterns of organizations' development. IBMRSS is considered as a layered model, requiring the organization of a variety of business entities and generating various services. The article solves the problem of organizational development at each level of the economic system of the region, with each of its elements, capable of creating the conditions for economic growth through their reduction in the innovation process.
\end{abstract}

Keywords - innovative business model, assessment methodology, organizational development, design, regional services, economic system.

\section{INTRODUCTION}

Designing an innovative business model of the regional service sector (IBMRSS) should be considered as an optimal sequence of applying scientific knowledge and methods to achieve the intended goal of increasing an innovative activity of business entities in the regional services sector. In this context, it is necessary to perceive the regional sphere of services as a system of a geographically separate economic space consisting of interconnected structural entities that are different in localization. After that, when consolidated into a single oriented aggregate, they provide themselves with an adaptive existence and development. This definition reflects the design capabilities of IBMRSS by highlighting the principle of self-sufficiency.

The result of designing IBMRSS is a business process, as the necessary sequence of actions that combine a set of views, conceptions, ideas aimed at identifying innovative development opportunities for both individual economic entities in the service sector and their regional symbiosis. IBMRSS is a "response" to the market conditions of the region, generated by the need for a focused process to ensure the competitiveness and efficiency of business entities in the service sector in a particular territory. The business entity that is most susceptible to innovation is formed and survives, which contributes to the expanded reproduction of innovative services and production factors that increase the welfare of the region's population.

The significant asymmetry in the economic development of the Russian regions makes it difficult to conduct an adequate federal and regional innovation policy aimed at creating a national market for innovation in the service sector. There is a need for the design of IBMRSS, contributing to the implementation of the national idea - innovative development of the Russian economy. The main factors influencing IBMRSS should be systematized in order to formulate a coherent and mutually beneficial federal and regional innovation policy. 


\section{LITERATURE REVIEW}

In the current development conditions of IBMRSS, the article highlights a nationwide specificity, reflecting the regional structure of the formation of the innovation space $[1,2]$. Historically, the conditions for the development of the Russian economy have formed a heterogeneous structure of economies of the territories that functioned in accordance with the administrative-state division of the country [3]. The specifics of building a Russian innovation economy based on the combined functioning of regions of different levels of development is a hallmark in the design of IBMRSS.

Partial autonomy of regional economies is a condition for the implementation of a unified approach to the target orientation of economic entities and the formation of regional organizational hierarchies [4], presented in the form of an innovative business model. Organization and ordering coordinated not only by market economic laws, but also by laws outlining the possibilities and powers of all subjects of the Russian Federation, creating a single legal field defined by regulatory legal acts and the activities of the regional administration.

The current situation with the imbalance in the development of regional economies determines the imbalance in the development of large cities in the region $[5,6]$. The imbalance in the development of various subsystems and sectors of the region's economy is due to both external factors historically in the national economy and many subjective factors, including those that arise due to underdevelopment or complete absence of any value, complexity, or systemic scheme, transition or mechanism to streamline the management process. This transition will allow us to start solving a whole list of socio-economic problems and to approach the balanced development of the totality of elements of the region's economy.

The basis for the transition of regional economic relations to an innovative path of development is the understanding of the region as a complex integrated, economic facility represented in the form of a system organization. The aim of regional economy is to provide conditions for the development of material production organizations, non-material spheres and production and social infrastructure, which is built on the basis of rational, integrated use of available natural raw materials, human, intellectual, geopolitical resources, as well as industrial, production, organizational and managerial potential.

The essence of IBMRSS design comes down to the formation of an oriented system of economic activity built on the basis of rational integration of goals and potentials of business entities that are coordinated by the project management system of the region. IBMRSS project management is considered as a form of integration of various organizations on a voluntary basis with the aim of creating an environment for its development through participation in regional projects that are consistent with the country's strategic development plan.

To reveal the essence and justify the design capabilities of IBMRSS, in the context of functioning of the innovation process management model $[7,8]$ it is necessary to apply a systematic approach at the regional level. Representation of IBMRSS in the form of a system allows you to take into account the multiplicity of goals of business entities acting as an object of project management, evaluate the influence of external and internal factors, present all possible relationships and relationships that arise during project management, determine the reasonable boundaries of the objects, the number of projects themselves and the level their relevance and adequacy to the prevailing conditions $[9,10]$.

The systematic approach applies the theory of knowledge and dialectics to the study of processes occurring in nature and society. Its essence is in the implementation of the requirements of the general theory of systems, according to which each object in the process of its research should be considered as a complex system and also as an element of a large system $[11,12]$.

Recognizing the systemic nature of the IBMRSS design, it is necessary to determine its system properties, forms and operating conditions. The main property that defines IBMRSS as a system is the validity of development priorities and the structure of its elements. This is reflected in the design in the form of the need to coordinate the goals of IBMRSS with the goals of the project participants, including at different stages of their development, both individual organizations and at different levels of the hierarchy within the framework of the regional approach to project management in view of the different importance of organizations in the proposed regional priorities innovation development. The main problem in the design and implementation of IBMRSS is the coordination of the goals of project participants with different status and level of development, generating multidirectional goals, often contradicting each other. In this aspect, the representation of IBMRSS as a system allows, through the property of focusing, to adjust the main goals that are part of the system of elements and to coordinate many goals of objects, excluding their alternativeness. Ultimately, the necessary and sufficient number of elements is determined, the goals of which will be consistent with the objectives of the project.

IBMRSS appears as a set of different organizations within the framework of a project management system that manifests its properties through the differentiation of elements. This is one of the ways to improve the organization of the process of achieving the goals set in the design process of IBMRSS. This position is expressed by the unambiguous dependence of the IBMRSS efficiency on the clarity and structure of the given final result, described by quantitative and qualitative parameters of the goal. The essence of this property is to search for a specific set of elements involved in the project, based on their goal-setting in the external environment. The more accurately the target and the IBMRSS are simulated, the closer the management process is to the goal itself. This property allows the system to get rid of unusual elements, from those project participants whose goals turned out to be inappropriate to the project goals.

By reducing the diverse properties of the region's economy, it is possible to formulate a full-fledged concept of the functioning of the regional services sector, thereby defining the purpose of IBMRSS, the management system, its 
components, outline the sphere of interests, principles and criteria necessary to form its organizational implementation.

The regional service sector is a complex organizational system consisting of a certain number of elements, the combined properties of which are sufficient and necessary to obtain the desired result [13-15], and also determine the features and establish design requirements for IBMRSS. The concept of the functioning of the regional services sector as an open, self-developing system is oriented in two directions. The first direction of the concept determines the need to target targeted innovation processes on the potential of the regional economy. IBMRSS should be oriented towards innovative development, taking into account the available resources and potential involved in the implementation of the project. In this case, the consolidation of legally independent organizations is necessary, which will be integrated within the framework of one project, designated in the rank of regional priorities. All project participants integrate their potential on the basis of mutual benefit. The idea put forward by M. Porter [16] about the approach to creating value chains in complex organizations is very interesting, which also supplemented the costing method based on the formation of the final product using the principle of a key resource and the processes associated with it.

The second direction of the concept indicates that IBMRSS creates the conditions for the balanced development of the material and non-material sphere of the region's economy by setting innovative processes in such a way as to exclude the dominance of some organizations over others, to achieve a balance of interests of business entities, to increase innovative activity in related industries; creating conditions for the growth of the social status of the region and improving the standard of living of the population.

\section{MethodOLOGY}

The design of IBMRSS should is a part of the economy, which includes all types of commercial and non-commercial services and that is a consolidated generalized category, including the reproduction of various types of services provided by organizations and individuals. The content of the service industry research area is an analysis of current trends and forecasts for the development of the economy, management; determination of scientifically based organizational and economic forms of activity, typologies of forms of the economic mechanism of organizations and complexes of industries; improvement of management methods and state regulation.

The object of the study is all the organizational and legal forms of organizations that provide the main activity in the service sector, production and social infrastructure, training, etc.

In the process of systematizing the factors that determine the possibility of innovative development of economic entities in the service sector of the region, it is necessary to highlight the elements of the IBMRSS design process (table 1).

The result of the IBMRSS design is a protocol for the purposeful management of the process of innovative development of service industry entities, which together form a geographically separate economic space, complementing the interconnected variety of activities of economic entities, which, when consolidated into a single oriented aggregate, provide themselves with innovative development.

TABLE I. ELEMENTS OF THE IBMRSS DESIGN PROCESS

\begin{tabular}{|c|c|}
\hline Elements & Interpretation \\
\hline $\begin{array}{l}\text { Project } \\
\text { management }\end{array}$ & $\begin{array}{l}\text { management of activities in the organization that require } \\
\text { constant leadership in the face of severe restrictions on the } \\
\text { timing, cost and quality of work }\end{array}$ \\
\hline Development & $\begin{array}{l}\text { irreversible, directed, regular change in matter and } \\
\text { consciousness }\end{array}$ \\
\hline $\begin{array}{l}\text { Innovative } \\
\text { development }\end{array}$ & $\begin{array}{l}\text { strategic development of economic facilities, carried out } \\
\text { through the systematic creation and implementation of } \\
\text { innovative technologies, products and services, focused on } \\
\text { achieving a high material, intellectual and spiritual level of } \\
\text { society, a high level of ecology and ensuring the safety of the } \\
\text { environment and human health }\end{array}$ \\
\hline Region & $\begin{array}{l}\text { a system of a geographically isolated economic space consisting } \\
\text { of interconnected structural entities of different localization that, } \\
\text { consolidating into a single oriented aggregate, provide themselves } \\
\text { with an adaptive existence and development }\end{array}$ \\
\hline System & $\begin{array}{l}\text { many elements that are in relationships and connections with } \\
\text { each other, which forms a certain integrity, unity }\end{array}$ \\
\hline $\begin{array}{l}\text { Business } \\
\text { entities }\end{array}$ & $\begin{array}{l}\text { individuals and legal entities, other subjects of civil law, } \\
\text { engaged in entrepreneurial activity or having the right to carry } \\
\text { it out, namely engaged in the production, sale or purchase of } \\
\text { goods }\end{array}$ \\
\hline \begin{tabular}{|l|} 
Services \\
sector
\end{tabular} & $\begin{array}{l}\text { a sector of the economy that provides tangible and intangible } \\
\text { services }\end{array}$ \\
\hline Localization & $\begin{array}{l}\text { assignment of something to a particular place, restriction of the } \\
\text { spread of the phenomenon, process to close borders, territorial } \\
\text { limits }\end{array}$ \\
\hline Process & $\begin{array}{l}\text { successive change of state of an object in time, stages of } \\
\text { development }\end{array}$ \\
\hline Ressources & $\begin{array}{l}\text { sources, means of production support: natural (raw materials, } \\
\text { geophysical), labor (human capital), capital (physical capital), } \\
\text { working capital (materials), information resources, financial } \\
\text { (money capital) }\end{array}$ \\
\hline $\begin{array}{l}\text { System } \\
\text { structure }\end{array}$ & $\begin{array}{l}\text { organization of relations and relations between subsystems and } \\
\text { elements of the system, as well as the actual composition of } \\
\text { these subsystems and elements, each of which usually has a } \\
\text { certain function }\end{array}$ \\
\hline Household & $\begin{array}{l}\text { totality of all means of production used by people in order to } \\
\text { meet their needs. }\end{array}$ \\
\hline
\end{tabular}

Solving the issue of assessing the effectiveness of using the innovative potential of the regional services sector requires a rethinking of the concept of the functioning of the territorial infrastructure.

\section{ASSESSMENT METHODOLOGY}

The methodology for assessing the effectiveness of using the innovative potential of the regional services sector is based on a number of principles:

- consistency - the need to analyze the innovative potential of the regional services sector as a system of interrelated elements: commercial and non-commercial institutions; bodies of federal, regional authority and local self-government;

- complexity - assessment, carried out taking into account all external and internal factors; 
- durability - the results of the assessment should take into account the principles of strategic development and determine the situation in the future;

- interconnectedness - innovative potential is an integral part of economic resources;

- continuous variability - assessment results are applicable for a limited time period;

- counter-intuitive behavior of complex Forrester systems - an assessment is carried out until it is fully consistent with the ideas of the author;

- stable disequilibrium - the potential depends on the degree of variability of individual indicators;

- sufficiency - the choice of indicators is carried out taking into account the degree of their influence on the efficiency of potential use;

- compliance - allows you to use the pattern of change of sufficient indicators.

Evaluation results should reflect the status and prospects of implementing IBMRSS. The result of evaluating the effectiveness of using the innovative potential of the regional services sector is presented in the form of an hourglass with a certain bifurcation point (figure 1).

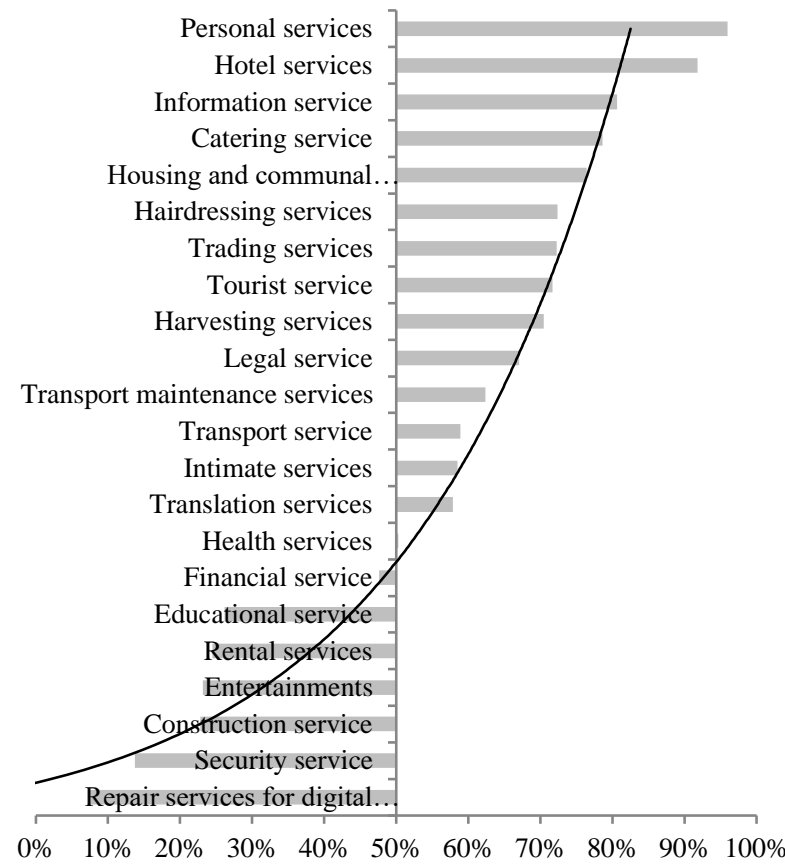

Fig. 1. Efficiency of using the innovative potential of the regional services sector

The assessment is based on the formula

$$
E=\sum_{i=1}^{n} X_{n} \cdot k_{n},
$$

where $X_{n}$ is the innovative potential of the regional services sector; $k_{n}$ - weighting factors;

$n-$ the number of sufficient indicators.

$$
X_{n}=\sum_{i=1}^{m} O_{m} \cdot \omega_{m},
$$

where $O_{m}$ - reference indicators;

$\varpi_{m}-$ importance factors;

$m$ - the number of reference indicators.

The structure of reference indicators is determined based on the analysis of domestic and foreign scientific literature, as well as on the basis of scientific research conducted in practice. The choice of reference indicators can be carried out by the researcher himself, depending on the goal-setting of the study and its individual capabilities.

It is possible to choose a system-forming indicator, which is dominant under appropriate conditions, and an assessment using this indicator more accurately reflects the specifics of the regional services sector.

The definition of reference indicators depends on the type of assessment - comparison of statistical data of the studied regional sphere of services relative to other regions of the Russian Federation: catering services, financial services, information services, housing and communal services, domestic services, rental services, intimate services, travel services, legal services, hotel services, security services, translation services, trade services, transportation services, entertainment, medical services, construction services, hairdressing services, technical services whom transport services, educational services, digital and home appliance repair services, cleaning services (figure 1). Reference indicators are defined as follows:

$$
O_{m}=\frac{O_{p}}{O_{x}} \cdot \beta,
$$

where $O_{p}$ is the base indicator for the region;

$O_{x}$ - basic average or reduced indicator of the compared regions;

$\beta-$ coefficient of reduction to the point system.

The recommended reduction factor is determined in the range of $0<\beta<1$. The importance factors are determined by expert judgment. Stages of the expert assessment:

1) division of experts into groups according to the level of competence;

2) formulation of the problem and the structure of the evaluated indicators;

3) description and classification of the problem situation goals, criteria and limitations;

4) list of measures is formulated, the implementation of which leads to a solution to the problem;

5) system of criteria for the evaluation of measures is determined; 
6) database of expert ranking of indicators is created;

7) each expert, using pairwise comparisons, evaluates the criteria (in the form of weighting and importance factors from 0 to 1 ) and, using a point-based rating system, ranks the selected groups of events;

8) calculation of group assessments of events, expert competency factors and concordance coefficient;

9) upon reaching a value of the coefficient of concordance of more than $80 \%$, experts produce results.

In the process of evaluating the effectiveness of using the innovative potential of the regional services sector, it becomes necessary to correct the activities of business entities in accordance with objective economic laws and patterns of development of organizations. As a result of the development of various types of ownership in the organizational structures of the service sector, we observe certain patterns that affect its functionality. These patterns are a consequence of the general managerial features of the IBMRSS implementation and include:

- delay. Society needs are dynamic and spontaneous;

- inadequacy. An individual who, refracting in his mind the meaning of the functions performed, always introduces his own interpretation of the procedure to their implementation;

- incompetence. This property manifests itself in full or partial isolation and attempts to adequately respond to all external disturbances.

As a result of the above regularities, the IBMRSS implementation process initially bears signs of inefficiency, due to the many residual elements whose functioning in the organization's structure is inappropriate.

\section{ANALYSIS}

In order to reduce the effects of negative factors induced by patterns of the functioning of the external environment, it is necessary to optimally organize the implementation process of IBMRSS, i.e. approach the solution of the problem of effective management of innovative development of economic entities in the regional services sector. This approach is based on the strategy of advanced design of functional management structures while ensuring systemogenesis from the existing systemic gene pool. This strategy corresponds to the concept of a tiered organizational system that will allow you to concentrate at various levels of the system a sufficient number of elements that have the necessary properties, the vertical and horizontal integration of which will allow you to acquire system properties that are able to take market changes ahead of schedule and adequately rebuild your functional structure. This approach is based on the principles of functional differentiation of elements, a clear distribution of functions by levels and elements, followed by the distribution of tasks in accordance with the goal-setting of each element.

The general IBMRSS implementation concept is based on the following principles:
- complexity - the presence in the system of a complete set of management functions;

- adequacy - a necessary and sufficient set of elements for environmental conditions;

- Integration - allows using vertical and horizontal integration methods to define flexible organizational forms within the system;

- cost-effectiveness - the distribution of tasks by specialized controls;

- adaptability - restructuring of the organization under the influence of external and internal factors.

The IBMRSS concept reflects the conditions for the formation of a problem-oriented system, built on the basis of a rational combination of innovative, resource-based organizational and managerial potentials of business entities in order to achieve the objectives in the regional economy using exogenous and endogenous resources. The development of such a system is coordinated by state authorities with the aim of orienting the efforts of project participants to regional goals and their consolidation through government measures to stimulate the activity of economic entities

An optimal implementation of the IBMRSS concept is possible with the level model of the control system, which allows concentrating at various levels a sufficient number of elements whose goals and objectives are capable of realizing the traditional sequence of the control process.

Correspondence of the set of elements that make up the system at all levels of its consideration to the essence and nature of the innovation process itself as an object of management, the policy of which adequately reflects the sequence of the target-oriented reproduction cycle innovative development.

The layered implementation model of IBMRSS is presented as a composition in the form of localized hierarchical levels, each solving its own separate control tasks and having a complex structure of horizontal connections and vertical relations.

The first level is setting goals for IBMRSS. The first level elements capable of adopting and shaping the goals of the IBMRSS are state and legislative bodies, as well as regional administration structures that have the corresponding status and powers.

The development of IBMRSS management goals can involve both individual interested parties and various public organizations that determine the management policy in the region and are either object of such management or individual elements of the innovation process. Such a conglomerate allows you to consolidate the goals and objectives of individual innovative projects integrated within the framework of the IBMRSS concept, which allows them to focus on solving key tasks.

The second level is the design of IBMRSS and the organization of the functioning of the innovation process. At this stage, the problem of optimal design of innovation 
management processes is solved by presenting a structural model of project management at the regional level. The main stages of model design will be: setting a generalized project management task based on the formed goal of managing innovative projects, evaluating the external and internal factors of the functioning of the innovation management process, determining direct and feedback functional dependencies of parameters that reflect the main characteristics of innovative processes as a project management object.

Structurally, the second level can be formed on the basis of the allocation of the main group of organizations or the leading organization in the region for innovation management, which fulfills the goals and objectives of the stages of the reproduction cycle.

The third level is the implementation of IBMRSS, in which a balanced model of project management of the innovation process is designed taking into account the potential of a real innovation object, in real time, taking into account the action of external factors and existing conditions and prerequisites. The task of the third level is to optimally adapt the design goals and objectives developed at the second level to the conditions of the real economy. At the same time, the possibilities of absorbing innovative objects, possible deviations from design conditions are evaluated and corrective actions are established.

In the framework of the third level, control procedures are implemented to implement the goals of the project management of innovations, assess non-compliance and develop preventive measures to coordinate the innovation process. In practice, this is expressed in the form of implementing innovative projects or business plans for innovative development at the level of production, technological and organizational and managerial processes, implemented within the framework of individual organizations included in the object of the innovation process.

The resulting organizational structure in the form of a level model for achieving the established goal, in accordance with the level of complexity and responsibility of the tasks to be solved, is the functional content of IBMRSS, the implementation of which is possible through the organizational structure of project management.

\section{DISCUSSION}

The design theory of IBMRSS is based on the conceptual foundation of the theoretical principles of growth and development of the regional economy. Theoretical principles are revealed in three main and sufficient directions: classical, neoclassical theories and the theory of cumulative growth. These theories orient the process of functional structuring of the region's economy towards the efficient use of the region's innovative potential. As a result, the creation of an infrastructure is able to generate competitive advantages in line with market conditions.

The design process of IBMRSS should be considered as a complex process of a tiered model, requiring the organization of a variety of business entities and generating services that are different in their types of activities and legal forms. This complex is ultimate, and its number is determined by the boundaries of the region. Organizations and processes arise in the region accept IBMRSS as an object.
In order to study the processes taking place in such an organizational union and to develop methods for the optimal use of the properties included in the elements of an object, it is necessary to consider this combination using a systematic approach. A systematic representation of the object is also necessary to study ways to eliminate the negative effects of factors of the external and internal environment.

Implementations of IBMRSS affect the organizational development of a geographically separate economic space and the acquisition by him in the course of evolution of the necessary and sufficient innovative potential at each level of the tier system and with each of its elements, capable of creating the conditions for economic growth through effective management of innovative processes. This development implies an evolutionary synthesis of the functions performed by the studied economic entities with the goal of greater adaptability in the external environment, reducing costs and losses from external factors and mobilizing innovative potential.

The implementation process of IBMRSS is associated with the features of the functional interaction of business entities and is a complex, interconnected mechanism with a complex system of horizontal and vertical links. From the position of a systematic approach, this mechanism can be represented by a stratified conceptual model in the form of three interpenetrating levels of function performance. The criteria for the differentiation of functions by levels are the categories of complexity and scale of the tasks to be solved, as well as the goals of economic entities and the possibility of achieving them.

\section{CONCLUSION}

The IBMRSS design process must consider the following key points:

- basis for the formation of the structure of the regional system of project management should be a previously identified set of functions of the designed facility;

- new structure is the result of the evolution of the previous development, the first inheriting all the positive accumulated earlier, the second receiving new development under the influence of new conditions and progressive trends in social development;

- among the many alternatives for the development of the structure of the designed object, the best option is which to a greater extent resolves the contradictions between the desired and the achieved.

The process of implementing IBMRSS is associated with the synthesis of the structure of the designed IBMRSS, the content of which is to conduct a focused search for organizational solutions based on an analysis of the decompositional set of functions of economic entities in the region and the selection of structural implementation options formed by their reduction. By combining these options, you can get some set of alternatives for building IBMRSS. The choice of the preferred combination is based on current restrictions and baseline conditions. 


\section{References}

[1] G. Beqiri, "Innovative Business Models and Crisis Management", Proc. Econ. and Finance, vol. 9, pp. 361-368, 2014. Retrieved from: https://doi.org/10.1016/S2212-5671(14)00037-9

[2] M. Johannsson, A. Wen, B. Kraetzig, D. Zhao Cohen, "Space and Open Innovation: Potential, limitations and conditions of success", Acta Astronaut., vol. 115, pp. 173-184, 2015. Retrieved from: https://doi.org/10.1016/j.actaastro.2015.05.023

[3] V. Smirnov, V. Semenov, E. Kadyshev, A. Zakharova, E. Perfilova, "Management Of Employment Promotion Institution In Russia", The Europ. Proc. of Soc. \& Behavioural Sci. (SCT 2018), no. 134, pp. 1157-1165, 2019. Publ. by the Future Acad. DOI: https://dx.doi.org/10.15405/epsbs. 2019.03.02.134

[4] D. Khairullov, "Challenges of Sustainable Development of Regional Economy in The Conditions of Russia's Accession to The World Trade Organization", Proc. Econ. and Finance, vol. 23, pp. 303-308, 2015. Retrieved from: https://doi.org/10.1016/S2212-5671(15)00488-8

[5] V.V. Smirnov, V.L. Semenov, A.N. Zakharova, E.N. Kadyshev, N.V. Bondarenko, "Self-Sufficient Urban Socio-Economic Space", Humanities and Social Sciences: Novations, Problems, Prospects (HSSNPP 2019). Advances in Social Science, Education and Humanities Research, vol. 333, pp. 159-164, 2019. Retrieved from: https://doi.org/10.2991/hssnpp-19.2019.29

[6] C. Sun, L.T. Chen, "Study on the urban state carrying capacity for unbalanced sustainable development regions: Evidence from the Yangtze River Economic Belt”, Ecolog. Indicat., vol. 89, pp. 150-158, 2018. Retrieved from: https://doi.org/10.1016/j.ecolind.2018.02.011

[7] K. Lintukangas, A.K. Kähkönen, J. Hallikas, "The role of supply management innovativeness and supplier orientation in firms sustainability performance”, J. of Purchas. and Supply Manag., vol. 25, iss. 4, 2019. Retrieved from: https://doi.org/10.1016/j.pursup. 2019.100558
[8] Q. Zhang, I. Deniaud, C. Lerch, C. Baron, E. Caillaud, "Process modeling of innovative design using Systems Engineering", IFACPapers OnLine, vol. 49, iss. 12, pp. 1579-1584, 2016. Retrieved from: https://doi.org/10.1016/j.ifacol.2016.07.805

[9] R.F. de Toledo, H.L. Miranda Junior, J.R. Farias Filho, H.G. Costa, “A scientometric review of global research on sustainability and project management dataset", Data in Brief, vol. 25, Art. 104312, August 2019. Retrieved from: https://doi.org/10.1016/j.dib.2019.104312

[10] A.G. Chofreh, F.A. Goni, M.N. Malik, H.H. Khan, J.J. Klemeš, "The imperative and research directions of sustainable project management", J. of Cleaner Product., vol. 238, iss. 20, Art. 117810, November 2019. Retrieved from: https://doi.org/10.1016/j.jclepro.2019.117810

[11] I.N. Caddy, M.M. Helou, "Supply chains and their management: Application of general systems theory", J. of Retail. and Consumer Services, vol. 14, iss. 5, pp. 319-327, 2007. Retrieved from: https://doi.org/10.1016/j.jretconser.2006.12.001

[12] W. Hofkirchner, M. Schafranek, "General System Theory", Philos. of Complex Syst., pp. 177-194, 2011. Retrieved from: https://doi.org/ 10.1016/B978-0-444-52076-0.50006-7

[13] B. Lin, G. Zhang, "Energy efficiency of Chinese service sector and its regional differences", J. of Cleaner Product., vol. 168, pp. 614-625, 2017. Retrieved from: https://doi.org/10.1016/j.jclepro.2017.09.020

[14] G. Zhang, B. Lin, "Impact of structure on unified efficiency for Chinese service sector - A two-stage analysis", Appl. Energy, vol. 231, pp. 876-886, 2018. Retrieved from: https://doi.org/10.1016/j.apenergy.2018.09.033

[15] F.F. Yang, O. Yeh, J. Wang, "Regional effects of producer services on manufacturing productivity in China", Appl. Geogr., vol. 97, pp. 263-274, 2018. Retrieved from: https://doi.org/10.1016/j.apgeog.2018.04.014

[16] M.E. Porter, Competition: Translated from English. Moscow: Publ. House Williams, 2002, 496 p. 